Describing humus in hot and dry regions, Pauli says (page 65), "During a normal year, the atmosphere in hot and dry lands takes up much more water evaporating from the soil surface and transpired by the plants than the amount of water which reaches the soil as precipitation." The normal laws of physics demand that water balance should be achieved so that, starting and finishing with the same moisture content in the soil, water falling as rain must equal that lost by evapotranspiration and drainage. Presumably Dr Pauli means that in hot, arid regions, potential evapotranspiration is much greater than rainfall. Many other similar points occur throughout the book.

The book is well produced (although the copy received for review lacked plates 2 and 3). The price appears somewhat high for the length of the text.

The subject matter is one that should stimulate ideas in soil fertility and one hopes that another may soon succeed where Dr Pauli has failed.

J. K. R. GAsSER

\section{STUDIES IN BIOLOGY}

\section{The Body Fluids and Their Functions}

By Garth Chapman. (The Institute of Biology's Studies in Biology, No. 8.) Pp. 68. (London: Edward Arnold (Publishers), Ltd., 1967.) 128. $6 d$.

\section{Guts}

The Form and Function of the Digestive System. By John Morton. (The Institute of Biology's Studies in Biology, No. 7.) Pp. 58. (London: Edward Arnold (Publishers), Ltd., 1967.) 12s. 6d. net.

\section{Microecology}

By J. L. Cloudsley-Thompson. (The Institute of Biology's Studies in Biology, No. 6.) Pp. $48+2$ plates. (London: Edward Arnold (Publishers), Ltd., 1967.) 128. 6d.

THe Institute of Biology's series "Studies in Biology" is for sixth-formers, their teachers and first-year undergraduates. It has, as its aim, the presentation of concise reviews of "limited biological topics in which recent progress has been most rapid and important". In this it reflects an essential need. The problem is not so much that changes in research and ideas in biology are rapid but that they are extremely variable. Inevitably a major breakthrough in one field can be paralleled by virtual inertia in another. In such circumstances the maintenance of up to date editions of large texts becomes a difficult and uneconomical task and small, limited texts have to be employed.

It is the intention of the series to provide accounts not only of topics but also of "the methods that have been employed in elucidating the problems with which they deal" and to provide "suggestions for practical work for the student which should form a sound scientific basis for his understanding". Presumably implicit in the fact that none of the books has an index is the idea that they should be read, as it were, in one mental breath without the need for the resuscitation of cross-reference. How do these three books match up to these aims ?

The Body Fluids and Their Functions is a comprehensive review. In parts it is so full of information and, in particular, taxonomic references that I suspect for the average student the physiological wood will get lost in the trees of specific names. It is chiefly at the first part of the book that this criticism can be levelled. It really is hard going with a first paragraph virtually a page long. What follows, however, is of great value. There are excellent sections on the dynamics of circulation, transport mechanisms and the homeostatic properties of the body fluids which are splendid examples of how the aims of the series can be achieved. Methods of investigations are integrated smoothly into descriptions of topics and the wider context of the subject is clearly demonstrated. The relation between physiology and ecology and, most important, the role of physical science and mathematics in biological study are well illustrated.

Guts is written in a lively and, at times, humorous style; a virtue indeed in a textbook. At the same time it loses nothing in academic quality. It is a tribute to the author that he manages to make a potentially dull subject interesting and provides an insight into what laymen (and we can include students among them) see as the biologist's eccentric fascination in rather disagreeable subjects.

The framework for the text is a functional classification: herbivores and omnivores, deposit feeders, carnivores, filter feeders and fluid feeders. Unfortunately, within each category we find a review of species which, although illustrating the variety of digestive systems, sometimes results in a rather barren catalogue of informa. tion. Possibly, it would have been better to use fewer examples and for more attention to be given to the gut as a selective barrier between the organism and the environment, emphasizing its ecological significance on the one hand and the physical processes involved in its functioning on the other. Methods of investigation are referred to, but mainly in a short appendix on practical work. There is little that illustrates how the methods and outcomes of investigations are related.

Microecology is not so much a review of the subject as a practical guide. The author is clearly more interested in getting students to find out about microecology than in telling them about the findings of microecologists; not a bad thing, but the result is that the book is a marked contrast to the other two. The depth and standard of presentation are much more elementary and clearly it is a book that would be used at the beginning of a course. Students would still need a review of the subject in its broader sense at the end.

The author argues the case for an autecological approach and through his review of measurement techniques and, particularly, his account of the ecology of cryptozoic animals which makes up virtually half the book, demon. strates the valuable part microecology can play in practical ecology classes. A chapter on microclimate and faunal distribution, however, is extremely shallow and the treat. ment of major ecological topics such as diurnal rhythm and food chains is appropriate to classes below the sixth form. Possibly the greatest disappointment is that no consideration is given to the place of microecology in applied biology. Pests of stored food products, and the role of soil organisms in agricultural practices, are only two examples that might have given the subject real meaning to the student.

Of the three books, I would select Body Fluids and Their Functions as being nearest to the aims of the series. But they all deserve a place in a school biology library. And a final comment: I am sure it would be very useful for students if indexes were provided. P. J. KeLLY

\section{ROOTS OF MODERN MEDICINE}

\section{Medicine at the Paris Hospital}

1794-1848. By Erwin H. Ackerknecht. Pp. xiv +242. (Baltimore, Md.: The Johns Hopkins Press; London: Oxford University Press, 1967.) 72s. net.

THE present-day clinical approach to the patient originated with the Hippoeratic physicians in fifth century Greece, and the interpretation of his disease on the basis of anatomy grew out of the Renaissance. The correlation, however, of these two, the findings in the living patient and those discovered in his body after death, did not receive widespread attention until the first decades of the nineteenth century. At this time the humoral pathology of the ancient Greeks was being replaced by morbid anatomy as an explanation of disease. Here then are the 